\title{
Ciudad y literatura. Cuando Sara Chura despierte de Juan Pablo Piñeiro
}

\section{María José Daona}

Universidad Nacional de Tucumán, Instituto de Investigaciones sobre el Lenguaje y la Cultura / CONICET/ Instituto de Interdisciplinario de Estudios Latinoamericanos, Argentina

\begin{abstract}
Resumen
El presente trabajo forma parte de una investigación mayor en torno al concepto de ciudad en la Bolivia del siglo XXI. Propongo que la literatura boliviana pone al descubierto las tensiones existentes entre las diferentes culturas que conviven y se superponen en la ciudad de La Paz. Los nuevos imaginarios urbanos le imprimen diversas significaciones al espacio y exploran las formas de convivencia de lo occidental y lo andino. Los personajes de los textos son transeúntes que, en sus pasos, le imprimen diversos sentidos a la "ciudad física" y dan cuenta de la existencia de un "discurso oculto" (Scott, 2000: 28) que devela los mecanismos de insubordinación de los sujetos oprimidos en las estructuras de poder.

En estas páginas me detendré en el análisis de la novela Cuando Sara Chura despierte (2004) de Juan Pablo Piñeiro. En el texto la ciudad aparece como una casa embrujada. El espacio se concibe como un tejido infinito de cruces de voces y mundos subterráneos, el cual quedó invisibilizado por la razón occidental. El transcurrir de los personajes por los intersticios de las calles y por espacios íntimos funciona como un mecanismo que evade el control y la vigilancia de la cultura dominante e implica la posibilidad de suturar la herida colonial.
\end{abstract}

PALABRAS CLAVE: Espacio, Ciudad, Bolivia

\section{City and Literature. Cuando Sara Chura despierte by Juan Pablo Piñeiro}

\begin{abstract}
The current paper is part of a larger research around the concept of city in XXI century Bolivia. It is my idea that Bolivian literature reveals the existing tensions between the different cultures that coexist and overlap in La Paz city. The modern urban imaginary invests space with several meanings and explores the shades of coexistence between
\end{abstract}


Western and Andean cultures. The characters are passers- by who give several meanings to the "physical city", and disclose the existence of a "hidden speech" (Scott, 2000: 28) that reveals certain mechanisms of rebellion in those who were oppressed within those structures of power.

In these pages, I will try to analyze the novel Cuando Sara Chura despierte (2004) by Juan Pablo Piñeiro. In its story, the city is portrayed as a haunted house. Space is conceived as an infinite trim of voices and underground worlds which were made invisible by western rational thought. The passing of the characters through the interstice of the streets and through intimate spaces, functions as a way to avoid control and surveillance of a dominant culture and implies the possibility of stitching the colonial wound.

\section{KEY WORDS: Space, City, Bolivia}

\section{Cidade e literatura. Cuando Sara Chura despierte de Juan Pablo Piñeiro}

\section{Resumo}

O presente artigo faz parte de uma pesquisa maior em torno do conceito de cidade na Bolivia do século XXI. Eu proponho que a literatura boliviana expõe as tensões existentes entre as diferentes culturas que convivem e se sobrepõem na cidade de La Paz. Os novos imaginários urbanos imprimem significados diferentes ao espaço e exploram os modos de convivência entre o ocidental e o andino. Os personagens dos textos são transeuntes que, nos seus passos, dão sentidos diferentes para a "cidade física" e dão conta da existencia de un "discurso oculto" (Scott, 2000: 28) que revela os mecanismos de insubordinação dos sujeitos oprimidos nas estruturas de poder.

Nestas páginas vou analisar a novela Cuando Sara Chura despierte (2004) de Juan Pablo Piñeiro. No texto a cidade aparece como uma casa assombrada. O espaço é concebido como um tecido infinito de vozes que se cruzam e mundos subterrâneos que permaneceram invisibilizados pela razão ocidental. O decorrer dos personagens pelos interstícios das ruas e pelos espaços íntimos funciona como um mecanismo que evita o controle e a vigilância da cultura dominante e implica a possibilidade de suturar a ferida colonial.

\section{PALAVRAS CHAVE: Espaço, Cidade, Bolivia}

"El mundo es la casa embrujada que todos habitamos."

Cuando Sara Chura despierte, Juan Pablo Piñeiro

\section{La ciudad en la literatura boliviana}

Observar La Paz desde la distancia, desde un arriba que dé cuenta del espacio planificado del urbanista o del cartógrafo, nos enfrenta a una serie de tensiones que se imprimen en los sujetos que la habitan, la recorren y le dan forma con sus pasos: la hoyada donde se asienta la ciudad está rodeada de montañas que funcionan a manera de resguardo espacial. En una de sus zonas más elevadas se encuentra la plaza Murillo, circundada por edificios gubernamentales y religiosos. Es allí donde se observa la 
ciudad ideada y planificada durante la colonia, que pretendía imprimirle un orden riguroso traducido en jerarquías sociales (Rama, 1998). Desde este centro, La Paz se diversifica y se transforma con el paso del tiempo hasta llegar a contener muchas ciudades en su interior.

Desde su independencia, La Paz se constituyó en el centro donde se localizaron los intelectuales que tuvieron el rol de interpretar el país y generar un discurso homogeneizante capaz de disuadir los problemas étnicos, económicos y sociales en donde fue preponderante la lógica occidental y modernizadora. ${ }^{1}$ A partir de la segunda mitad del siglo XX, la literatura atraviesa un proceso de urbanización y construye como su epicentro La Paz, rompiendo con aquel discurso a partir de la problematización de universos contrapuestos que habitan un mismo espacio. Entre ellos están: el mundo occidental, mestizo-criollo y desarrollista, y el mundo andino donde se ubica lo indígena y anticolonial vinculados a las periferias urbanas y a lo marginal. ${ }^{2}$

Las primeras lecturas en torno a la literatura urbana colocan a Los deshabitados (1959) de Marcelo Quiroga Santa Cruz como el texto que inaugura lo que Luis Antezana (1985) denomina "la novela de la ciudad". Es interesante observar que este ciclo se abre despojado de lo indio ya que el escritor cochabambino da cuenta de los conflictos y contrariedades de la clase media boliviana. En un texto posterior, Antezana sostiene que la novela de ciudad se consolida en 1979 con la publicación de Felipe Delgado de Jaime Saenz y señala que la nueva narrativa urbana se localiza en las márgenes y se ocupa de personajes excluidos. Sus protagonistas son transeúntes, lo que supone "una estrecha relación con su entorno indígena y, claro, andino" (2013: 59). En la escritura saenciana, lo indígena se incorpora en la figura mitificada del aparapita que, además, le sirve para construir una imagen de autor.

Blanca Wiethüchter (2003) sostiene que existió en Bolivia una necesidad de construir centros urbanos que se diferenciaran de España como una urgencia de autorrepresentación. Esto llevó a crear "una dimensión biográfica de las ciudades, intentando definir un imaginario particular en contra de toda homogeneización" (2003: 2). Enuncia cuatro textos $^{3}$ donde se sostienen los imaginarios urbanos de las diferentes ciudades bolivianas, en el caso de La Paz menciona a Felipe Delgado, donde se construye un espacio fantasmagórico, vinculado a un "subsuelo profundo que define el país y que

\footnotetext{
1 Algunos escritores que encarnan esta tendencia son Augusto Céspedes, Franz Tamayo, Alcides Arguedas, Osar Cerruto, entre otros. A pesar de las temáticas abordadas por esta literatura y sus descripciones de la vida rural son textos escritos siempre desde la ciudad. Dice Blanca Wiethüchter (2003) que pertenecen a "un imaginario ciudadano que interpreta el campo o la mina" (8). A esto se le puede agregar que, si bien la ciudad se mantiene ausente, el lenguaje utilizado y las ideas sobre lo nacional y sobre el país le dan forma al espacio urbano mucho más que al rural.

2 Guillermo Mariaca Iturri en La palabra autoritaria (1990) analiza la literatura boliviana a partir de la oposición palabra autoritaria - palabra democrática. Muestra la hegemonía planteada por la cultura populista que se enfrenta a las voces acalladas de la cultura popular. La primera organiza un "horizonte de lo posible" que monopoliza los discursos. Frente a ésta emerge el espacio de lo imposible formado por murmullos que se convierten en prácticas subversoras donde se incluyen las voces de la tradición oral, de las clases subalternas, de la calle, etc. Mariaca Iturri, para analizar el funcionamiento de la literatura boliviana en el período 1930-1985, diferencia la cultura del poder y la cultura popular y muestra cómo las prácticas culturales se espacializan. La cultura del poder tiene que organizarse para preservarse y lo hace a través de museos, universidades, iglesias, etc. La cultura popular se construye cotidianamente desde la calle, el barrio y diferentes espacios donde se producen relaciones entre sujetos sociales. La literatura boliviana, hasta la caída del Movimiento Nacionalista Revolucionario en 1964, fue producida y dirigida por la clase dominante. Para él, es la literatura minera la que permite el ingreso de lo popular al sistema literario boliviano. Los protagonistas sociales tienen una importancia fundamental a la hora de historiar esta narrativa y también la influencia de las posiciones políticas e ideológicas de los escritores. Las dicotomías palabra democrática - palabra autoritaria, discurso populista - discurso popular, lo posible - lo imposible, le sirven a Mariaca Iturri para explicar el desarrollo de la literatura boliviana en relación con los cambios históricos, políticos e ideológicos que ocurren en el país.

3 Los otros textos que menciona son: para Potosí, Historia de la Villa Imperial (1705-1736) de Bartolomé de Arzans de Orsúa y Vela; para Cochabamba, Juan de la Rosa (1885) de Nataniel Aguirre y para Santa Cruz, Jonás y la ballena rosada (1987) de Wolfango Montes Vannucci.
} 
es el de ser un saco de aparapita en el que la unidad no depende sino de un no mísero pero mágico hilo que mantiene el hilván" (2003:3).

En Felipe Delgado el conjunto de remiendos del saco del aparapita representa "un tejido vivo" (Antezana, 2013: 124) donde están guardadas las experiencias, los secretos y misterios de una vida. Este saco se erigió en una potente metáfora que representa un eco de la diversidad de la ciudad "por medio de sus restos y deshechos". Es también la posibilidad de pensar lo que Leonardo García Pabón (1998) llama la "patria íntima" en oposición a la idea de nación como autoridad proveniente de un discurso social ligado al Estado. García Pabón (2008) también plantea que la figura del aparapita en la prosa saenciana marca el fin del indigenismo. Y agrega:

Después de la creación del aparapita como ser urbano, como el centro místico de la ciudad ya no se puede escribir literariamente de indígenas bajo la típica caracterización como víctimas del sistema social. Su condición social, sea la de pobreza, locura o rebeldía, no es óbice para que su destino no sea algo que está en sus manos y que esté íntimamente ligado a la ciudad, el espacio de las definiciones culturales, sociales y políticas de la nación. El indio, que en la ciudad se convierte en aparapita, como dice Saenz, también se convierte en sujeto de la historia, y deja de ser objeto victimal de la misma. (2008: 10)

Jaime Saenz publica "El aparapita de La Paz" en 1968; es decir que este texto se hace eco de una serie de transformaciones que están sucediendo en los imaginarios políticos y sociales. La consecuencia es poder pensar al indio no sólo desde la ciudad sino también en ella. La construcción del aparapita abre un horizonte antioccidental e imprime la posibilidad de representar la ciudad desde una diversidad de miradas. Es una imagen que se amplifica y que, en la escritura posterior vinculada a la ciudad, da la posibilidad de hablar no ya de lo indio, como lo sostenía García Pabón, sino de lo andino. En esta dirección, cuando Ximena Soruco Sologuren (2011) analiza los modos de apropiación de la ciudad por parte de indígenas y cholos durante los siglos XIX y XX, sostiene que el nomadismo cholo construye las ciudades bolivianas en un gesto de apropiación de la "cartografía de poder". Si bien en su trabajo no indaga en la escritura de la segunda mitad del XX, dice respecto a Jaime Saenz que en el deambular por la ciudad marginal de Felipe Delgado se deshacen los discursos de nación e identidad bolivianas. Y añade:

La cantina es la única posibilidad de constitución de comunidad, un espacio de reconocimiento del protagonista, él deviene aparapita ahí, pero también es un lugar de tránsito. [...] Felipe Delgado, entonces, es el recorrido de un criollo que se transforma en aparapita, el eslabón más bajo de la matriz colonial, sin comunidad ni identidad o aquella tan provisional como la que se forma en la bodega. Su historia es un "tránsito", un ir y venir las calles paceñas marginales, descubriéndose en el acto de descubrir la ciudad y abandonarse a ella. (2011:236)

Es por esto que considero a Saenz como uno de los escritores que inaugura nuevas posibilidades de representar la ciudad. Junto a él, y a tono con estas modificaciones, se erige la escritura de Jesús Urzagasti. Indudablemente, entre ambos escritores existen temas en común que podrían sintetizarse en la intención de mirar la realidad desde una perspectiva que devela lo oculto, el secreto y lo invisible. En el caso de Saenz, la construcción de la bodega como eje de una poética genera una grieta en la "realidad real" donde el alcohol rompe el cerco que divide la vida de la muerte. El aparapita posibilita romper el cerco de la mirada monolítica del mundo occidental e invita a mirar con un tercer ojo, en términos de Javier Sanjinés (2014), donde ingresan otras interpretaciones del mundo. 
El caso de Urzagasti es particular ya que el mismo autor es un migrante que intenta a lo largo de su obra poner en diálogo diferentes culturas que confluyen en la ciudad de La Paz. Es una escritura profundamente urbana que mira lo rural desde la nostalgia. Respecto al lugar que ocupa Urzagasti en la literatura boliviana, dice Wiethüchter (2003) que el autor rompe con la dicotomía campo-ciudad porque en él aparece el imaginario campesino que migra a la ciudad. Además:

Rompe las polaridades regionales o nacionales, las fronteras entre los vivos y los muertos, las orillas entre el sueño y la vigilia, los límites entre lo real y lo irreal, fundando un espacio que trasciende estas polaridades a favor de un lugar que obra la sincronía, es decir, que rompe con toda linealidad histórica, para hacer posible una convivencia luminosa de todas las esferas de lo humano por encima de los límites que imponen las oposiciones antagónicas. (2003: 8)

A los fines de pensar los imaginarios urbanos que construye la literatura, ${ }^{4}$ el gran salto lo encontramos en su última novela, escrita en un momento intersticial de la vida política boliviana: Un hazmerreír en aprietos (2005). Dicho texto marca un giro, en el marco de su obra, y la ciudad se erige como zona de conflicto, lugar donde se encuentran las muchedumbres y se cruzan diferentes identidades. Por lo tanto, la escritura en torno a lo urbano debe hacer resonar miles de voces que aseguren su supervivencia. ${ }^{5}$ Este texto evidencia un proceso de cambio en la vida social, política y cultural que se viene gestando desde sectores indígenas y sindicales y que concluirá con la llegada a la presidencia de Evo Morales en 2006.

Teniendo en cuenta estos elementos propongo una nueva manera de pensar la ciudad en la novela boliviana del siglo XXI, que pone al descubierto las tensiones existentes entre las diferentes culturas que conviven, se superponen y le imprimen diversas significaciones. Este movimiento, que tiene como precursores a Saenz y Urzagasti, explora las formas de convivencia de lo occidental y lo andino en la ciudad. Para esto me centraré, en estas pocas páginas, en Cuando Sara Chura despierte ([2003] 2014) de Juan Pablo Piñeiro.

\section{La ciudad tejida}

En la cima de la montaña comienza el recorrido del Pax' paku, ahora llamado César Amato, personaje principal de la novela que nos ocupa. Tras descender de las alturas camina por las calles y recovecos de La Paz hasta llegar a la habitación del tercer piso de la "Selva oscura" donde está Sara Chura. Ella le pide que encuentre al muerto que respira durante la fiesta del Gran Poder, ${ }^{6}$ para así despertar. Este "viajero en tránsito",

4 La escritura de Jesús Urzagasti no ha despertado el interés de la crítica como es el caso de Jaime Saenz. Ana Rebeca Prada es la única autora que se ocupó de la novelística urzagastiana pensada como totalidad. Además de escribir diversos artículos, su libro Viaje y narración: Las novelas de Jesús Urzagasti (2002) es un texto insoslayable para aproximarse al autor. Este vacío me llevó a estudiar la obra literaria completa del autor en cuestión. Algunos trabajos que pueden consultarse son: "Viajar es buscar la libertad. En torno a El último domingo de un caminante de Jesús Urzagasti” (2015), "El espacio troceado. En el país del silencio de Jesús Urzagasti” (2017), "La memoria incesante. Los tejedores de la noche de Jesús Urzagasti” (2018) y “La escritura de Jesús Urzagasti: Poética de la intemperie” (2019). Próximamente se publicará un libro de mi autoría titulado Guardián del silencio. La escritura de Jesús Urzagasti por la editorial 3600.

5 Estas ideas fueron trabajadas en "Jesús Urzagasti: lecturas camufladas y latentes" que publiqué en el libro Siluetas de papel (2011), coordinado por Carmen Perilli y María Jesús Benites.

6 La fiesta de Jesús del Gran Poder se celebra entre mayo y junio en la ciudad de La Paz. Allí participan alrededor de sesenta y tres fraternidades folclóricas que hacen su ingreso bailando y exponiendo sus trajes en un gesto de agradecimiento a la divinidad del Señor Jesús del Gran Poder. Sus orígenes se remontan al siglo XVII cuando se funda el Convento de las Madres Concepcionistas, pero su forma actual la adquirió en el transcurso del siglo XX. A cambio de que el Tata del Gran Poder cumpla los deseos de las personas se le promete seguir bailando. Según Germán Guaygua, "la Fiesta del Gran Poder es el escenario donde se expresan tanto los procesos de modernización y de globalización como los de reivindicación étnica, actúa como el «lugar» donde se viabiliza una sumatoria de identidades en la que 
en cada uno de sus pasos, le da forma y existencia a la gran ciudad del altiplano, ahora convertida en sujeto. La ciudad trasformada en un caudaloso río es un espacio que guarda secretos y silencios; es la casa embrujada que se debate entre lo múltiple y el fragmento. Cada uno de los pasos de nuestro protagonista es un trazo que configura un texto urbano caracterizado por la apropiación del espacio y, en consecuencia, por su construcción y reconstrucción.

Subidas y bajadas, pasillos, recovecos, habitaciones misteriosas y casas sin ventanas son algunos de los espacios que recorren los personajes. Todos son migrantes que crean en su tránsito una ciudad subterránea. "El mundo es la casa embrujada que todos habitamos" (Piñeiro, 2014: 11) dice Amato mientras observa el espacio circundante. "Las personas somos como el forastero que llega a medianoche a una casa abandonada" (ibid.) agrega antes de comenzar su descenso.

La Paz se construye como un lugar abandonado que se va poblando a partir de lo extraño, lo ajeno, lo que viene de afuera. Fundada como "lugar de paso entre Potosí y Cuzco, sus habitantes serán siempre seres de paso" (Piñeiro, 2014: 51). Con la llegada de Amato se da un proceso de apropiación del espacio atravesado por la magia y el embrujo. Tres personajes hechizan la ciudad. Sus identidades son escurridizas y cambiantes e instauran la duda y la incertidumbre en el lector: ¿quién es el Pax'paku? ¿Qué representan Sara Chura y el muerto que respira? ¿Por qué para que Sara Chura despierte es necesario encontrar al muerto que respira? ¿Qué tiene que ver todo esto con la construcción de la ciudad?

Magdalena González Almada sostiene que las preocupaciones de Piñeiro son "reconocer un lugar en el mundo, interpelarlo, increpar y romper la lengua que habla y la procedencia del saber dominante, ajustar y rescatar las voces interiores más profundas que ocupan y fracturan al sujeto ch ixi, abigarrado" (2017: 123). En esta dirección sostengo que los lugares transitados se erigen en espacios sociales autónomos que se construyen a partir de prácticas de resistencia y plasman una visión de mundo contrahegemónica.

La ciudad es un lugar practicado de donde puede emerger lo que James Scott (2000) denomina "discurso oculto". Este discurso devela los mecanismos de insubordinación de los sujetos oprimidos en las estructuras de poder. Dice Falsoafán, uno de los personajes dedicado a inventar objetos, en una escena donde le dicta sus pensamientos a su ayudante, el Puntocom: "se ha consolidado un mundo limitado, resultado de siglos enteros en que el ser humano ha olvidado su pertenencia a los ciclos naturales que corren subterráneos y silenciados, por debajo de esa casa sin ventanas que inocentemente llamamos realidad" (Piñeiro, 2014: 45).

Lo subterráneo y silenciado son elementos constitutivos de un espacio otro que no fue protagonista de la historia. Mundo anulado por un "vanidoso occidente" que se basa en la lógica "verdad-realidad-poder". La verdad es concebida como una quimera que nos gobierna para negar la fragilidad de la vida del hombre; la hija autoritaria y masculinizada de esta verdad es la "realidad". Ambas construyeron un "mundo de jerarquías artificiales" que se funda en la noción de poder. El resultado es una fisura, un hueco, una rotura que deja de lado los "caminos entrelazados" del hombre que posibilitarían crear un espacio "incluyente, múltiple, mutable, acumulativo y no una realidad petrificada, normalizadora y amarrada con saña a las profundidades de nuestra existencia" (2014: 46).

intervienen los relatos y las representaciones de los sujetos sociales. Desde diferentes miradas, diferentes varias ciudades aparecen en el imaginario social y dan cuenta de una estética urbana, síntesis de esta «mixturación» de prácticas y representaciones". (2003: 171) 
Esta reflexión dictada por Falsoafán, por falta de papel, no queda plasmada. Son palabras extraviadas que están destinadas a "no ser escritas". Frente a esto, deciden usar el papel de los libros del personaje en un gesto que reescribe o sobreescribe la biblioteca occidental. El primero que eligen es un libro de arquitectura donde se recupera la idea del mundo como casa embrujada:

[...] la arquitectura [es] el rito mágico de nombrar un espacio en el mundo. [...] Todas las casas de todas las comunidades están construidas de la misma forma, siempre consagradas a tres espacios fundamentales: el centro, el patio y el secreto. [...] Ese secreto [...] es también el centro de una arquitectura mayor: la arquitectura del mundo habitado por las criaturas humanas. (2014: 46)

En esta concepción de los espacios, los caminos son una opción de habitar el mundo. En la ciudad que crea Piñeiro, el centro es la habitación de la Selva oscura donde duerme Sara Chura. Es el espacio mágico donde todo confluye. En el ir y venir, en el subir y el bajar las calles y recovecos de la ciudad se construyen puentes y líneas que unen pasado-presente y futuro como una nueva forma de habitar. Ella le pide a César Amato, ahora convertido en detective privado, que encuentre al muerto que respira. Todo ocurre en la víspera del Gran Poder, una fiesta que "se funda en los márgenes de lo ordinario, que se erige en función y dimensión a la fuerza social: el poder de construir comunidad" (Vargas e Ibáñez, 2010: 43).

En el texto "La fiesta: el tejido de los cuerpos" (2010) sostienen sus autores que en ella se tensa una relación entre tradición y modernidad, y agregan: "El Gran Poder es una manera de volver al pasado modelando y poniendo en escena el fruto del presente" (Ardaya et all., 2010: 66). Me interesa destacar la idea de "poner en escena" como la construcción de un espacio contrahegemónico donde, en términos bajtinianos, el carnaval es su expresión. Desde esta perspectiva, la novela construye un espacio social donde resuena el discurso oculto que se manifiesta a partir de la magia, vinculada a lo ancestral que pervive y habita la ciudad.

La principal característica del Pax'paku es su capacidad para mudar de piel: el actual César Amato, detective privado, fue también César Mateo, dedicado a la prestidigitación; el curaca Amator, adivinador del futuro; Cesaram Ato Rameses, encantador de serpientes y palomas; Cesáreo Amadeo, actor de radionovelas, entre otros. ${ }^{7}$ En su encuentro con Sara Chura él se siente desnudo, sin pieles. Ella se dispone a hablar el idioma de Amato frente a lo que el personaje reflexiona: ¿cuál es ese idioma?: no era el castellano y en cada palabra pronunciada se escondía otra; "su idioma probablemente era el conjuro de un ser que mutaba para no romperse" (Piñeiro, 2014: 20-21).

En este encuentro, la realidad comienza a ser percibida como grieta. Ya no es la "realidad común" que diseñan las personas en su tránsito veloz, sino que, en el idioma hablado con Sara Chura, emergen ecos, fragmentos y silencios como elementos constitutivos de un mundo subterráneo. El idioma de los personajes hace visible lo invisible y revela "la ciudad ancestral que duerme en las profundidades de La Paz" (2014: 118).

La novela devela la existencia de una rotura territorial metaforizada en la presencia del muerto que respira. ¿Y quién es el muerto que respira? Este muerto representa

7 La idea de mudar de piel me recuerda a Jursafú y El Otro, personajes de En el país del silencio de Jesús Urzagasti. El Otro, en un diálogo que tiene con Jursafú, reconoce que un individuo es muchos sujetos y que la unidad no puede pensarse de manera lineal. Descubre que "lo habitaban infinidad de seres, amaestrados y reducidos a tres individuos, a dos, rara vez al presentimiento de la unidad”. (231) En este mismo diálogo Jursafú comenta que en el pasado no sólo fue Fielkho (personaje de la primera novela de Urzagasti, Tirinea) sino también Kinixio y Goter, entre otros. 
a los niños con hambre que mueren por diversas enfermedades; a las mujeres sin nombre ni edad, ni sueños ni vida, que duermen en huecos por trabajar en "casas de familias"; a los cuerpos abandonados en los caminos; a las ancianas que mueren de frío; a los mineros; a los soldados que mueren como perros; es también Sinmar el marino, impedido de navegar por otros mundos, estático en las "aguas turbias y estancadas, donde se deposita toda la mierda del país, como un pretexto para justificar nuestra pobreza" (2014: 72).

Buscar al muerto que respira implica cruzar espacios. Es un deambular, entendido como un "modo de poblar la tierra". Tim Ingold, en su estudio sobre las líneas, advierte que en el tejido cada puntada es un nudo que, en sus interacciones, van formando las superficies. Todo junto constituye una malla en la que el nudo es un lugar y los hilos con los que está trazada representan un deambular. Deambular-poblar implica participar "desde dentro en el proceso continuo de venir al mundo [...] dejando un itinerario vital, (y contribuyendo) a su trama y textura" (Ingold, 2015: 119).

Es así como, en cada paso, los personajes le dan forma a una "ciudad tejida". En cada uno de los nudos se entraman las voces de los diversos muertos que respiran. "Téjeme", le pedirán los personajes a Sara Chura. Cada uno de ellos es un hilo suelto en el mundo de jerarquías, creado por dios, y dominado por la razón y la ciencia. El otro mundo está hecho de proporciones y es allí donde se pueden elaborar los tejidos "que nos deberían unir" (2014: 103). El primero ha creado una realidad excluyente y de máscaras. Tejer la ciudad es un gesto de sutura y resistencia. Dice Sara Chura:

Somos las letras de una palabra infinita que cambia cada segundo [...]. Si mi voz se ha cruzado con la tuya entonces ya estamos tejidos para adelante, para atrás, para siempre. [...] Se forman los nudos, se crean figuras y nuestra historia es la trama que se teje en la gran urdimbre de los ancestros. Y entonces nadie muere cuando somos tejidos y tejemos a cada instante infinitos caminos. (2014: 81)

Tejer la ciudad es la posibilidad de un diálogo que se funda en el encuentro, en el cruce de voces, en la pervivencia de lo ancestral que Sara Chura representa. Tejer la ciudad es "salir de escena": escapar del ojo monolítico de la razón occidental y hacer emerger ese discurso oculto que vive más allá de la lógica de la dominación. Tejer la ciudad es "crear comunidad"; es romper con la idea grandilocuente de nación que domesticó y le puso límites geográficos y jurídicos a la alteridad indígena (Rivera Cusicanqui, 2018: 119). La idea de "crear comunidad" está asociada a la construcción de un tejido donde conviven los contrarios: lo negro y lo blanco, lo indio y lo occidental, lo alto y lo bajo, el centro y la periferia, el pasado y el futuro. Es un acto comunicativo y de encuentro que no implica negar la fisura colonial sino abrir la posibilidad de una sutura a partir de la articulación de presentes y pasados de sujetos que vivieron al margen de los discursos estatales para subvertir los mandatos coloniales.

Juan Pablo Piñeiro nos propone una escritura a contrapelo del tiempo abstracto y vacío e instaura el tiempo del ahora que se convierte en punto de encuentro entre el pasado y el futuro y, con esto, en espacio hecho para habitar. Este tiempo-espacio vivo marcha a contrapelo de la nación que lloraba "en el regazo de la muerte" (Urzagasti, 2007: 405) y construye, junto a sus mayores, un país que es también la vuelta al pago, el retorno a la bodega. Cuando Sara Chura despierte es una novela de fronteras transgredidas, novela de memorias tejidas que espera el día en que Sara Chura finalmente despierte. 


\section{Q Bibliografía}

» Antezana, L. H. (1985). “La novela boliviana en el último cuarto de siglo”. En Sanjinés, J., Tendencias actuales de la literatura boliviana (pp. 27-54). Valencia, Institute for the study of ideologies \& literatura.

"Antezana, L. H. (2013). "El giro urbano de la novela en Bolivia". Trabajo presentado en el $6^{\circ}$ Foro de Escritores Bolivianos. Rupturas literarias de la novela boliviana del siglo XX. Cochabamba, Centro Simón I. Patiño.

» Ardaya, S.; De Urioste, L.; Molina, M. C. y Ticona, I. (2010). “La fiesta: el tejido de los cuerpos”. En Mariaca Iturri, G.; Gonzales, L. J.; Rocha Velasco, O. y Catalayud Criales, O. (Comps.), Literatura y fiesta (pp. 55-88). La Paz: IEB.

» Bajtín, M. (2003). La cultura popular en la edad media y el renacimiento. Madrid: Alianza.

»Daona, M. J. (2011). “Jesús Urzagasti: Lecturas camufladas y latentes”. En Perrilli, C. y Benites, M. J. (Comps.), Siluetas de papel. El autor como lector (pp. 111120). Buenos Aires: Corregidor.

"Daona, M. J. (2015). Viajar es buscar la libertad. En torno a El último domingo de

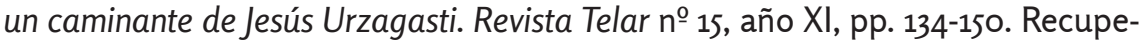
rado de <http://revistatelar.ct.unt.edu.ar/index.php/revistatelar>.

»Daona, M. J. (2017). El espacio troceado. En el país del silencio de Jesús Urzagasti. Revista Pilquen, vol. 20, no 1, pp. 36-43. Recuperado de <http://revele.uncoma. edu.ar/htdoc/revele/index.php/Sociales/article/view/1621>.

»Daona, M. J. (2018). La memoria incesante. Los tejedores de la noche de Jesús Urzagasti. Revista Revell, vol. 1, nº 18. Universidade Estadual de Mato Grosso do Sul, pp. 56-8o. Recuperado de <file:///C:/Users/Pablo/Downloads/DialnetLaMemorialncesante-6514370.pdf>.

»Daona, M. J. (2019). La escritura de Jesús Urzagasti: Poética de la intemperie. Revista Chilena de Literatura, no 99. Universidad de Chile, pp. 203-229. Recuperado de <https://revistaliteratura.uchile.cl/index.php/RCL/article/ view/53020/55599>.

» García Pabón, L. (1998). La Patria íntima. Alegorías nacionales en la literatura y el cine de Bolivia. La Paz: CESU-UMSS/Plural.

»González Almada, M. (2017). Gestos descoloniales: reverso y diseminación. Una lectura a partir de Principio Potosí Reverso y Cuando Sara Chura despierte e Illimani púrpura de Juan Pablo Piñeiro. Revista Língua y Literatura, vol. 19, ํㅜ 33 , pp. 116-130.

» Guaygua, G. (2003). La fiesta del Gran Poder: el escenario de construcción de identidades urbanas en la ciudad de La Paz, Bolivia. Temas Sociales, nº 24, pp. 171-184.

» Ingold, T. (2015). Líneas. Una breve historia. Barcelona: Gedisa.

»Mariaca Iturri, G. (1990). La palabra autoritaria. El discurso literario del populismo. La Paz: Tiahuanakos.

»Piñeiro, J. P. (2014). Cuando Sara Chura despierte. Córdoba: Portaculturas.

"Prada, A. R. (2002). Viaje y narración: Las novelas de Jesús Urzagasti. La Paz: Sierpe. 
»Quiroga Santa Cruz, M. (2010). Los deshabitados. La Paz: Plural.

»Rama, A. (1998). La ciudad letrada. Montevideo: Arca.

"Rivera Cusicanqui, S. (2018). Un mundo ch'ixi es posible. Ensayos desde un presente en crisis. Buenos Aires: Tinta limón.

»Saenz, J. (2007). Felipe Delgado. La Paz: Plural.

»Saenz, J. (2014). Prosa Breve. La Paz: Plural.

»Sanjinés, J. (2014). El espejismo del mestizaje. La Paz: Fundación PIEB.

»Scott, J. (2000). Los dominados y el arte de la resistencia. México: Era.

»Soruco Sologuren, X. (2011). La ciudad de los cholos. Mestizaje y colonialidad en Bolivia. Siglos XIX y XX. Lima, Institut français d'études andines.

»Urzagasti, J. (2005). Un hazmerreír en aprietos. La Paz, OFAVIM.

» Urzagasti, J. (2007). En el país del silencio. La Paz: Creativa.

»Vargas, F. e Ibáñez, J. A. (2010). "La imaginaria comunidad del gran poder”. En Mariaca Iturri, G.; Gonzales, L. J.; Rocha Velasco, O. y Catalayud Criales, O. (Comps.), Literatura y fiesta (pp. 41-51). La Paz: IEB.

»Wietüchter, B. et all. (2003 [2002]). Hacia una historia crítica de la literatura en Bolivia. Tomo 1. La Paz: Fundación PIEB. 